\title{
AiMT
}

Advances in Military Technology

Vol. 13, No. 1 (2018), pp. 95-106

ISSN 1802-2308, eISSN 2533-4123

DOI 10.3849/aimt.01226

\section{Evolution of Flight Data Recorders}

\author{
M. Dub*and J. Parizek \\ Faculty of Military Technology, University of Defence in Brno, Czech Republic
}

The manuscript was received on 6 December 2017 and was accepted after revision for publication on 1 May 2018.

\begin{abstract}
:
A flight recorder, commonly known as a black box, is considered the most important witness in the investigation of air accidents. Flight recorders have been considered important parts of onboard equipment for both military and civilian aircraft all over the world already from 1950s. They are used not only for flight evaluation after an unexpected event, but also for a pilot training, pilot skills assessment, diagnostics of on-board systems, and evaluation of aircraft systems as a whole. Thus, these flight recorders contribute to high aircraft reliability and aviation operation safety. This article focuses on Automatic Deployable Flight Recorders (ADFR), currently not often used in the military or civilian aircraft. ADFRs are mainly used for aircraft that fly over vast water areas as classic concept recorders were hard to find when the aircraft crashed into water. This deployable recorder is a reliable flight safety system used e.g. in US Navy F/A-18 multirole combat jets. In addition, creation of this article was inspired by the change in ICAO Standards and Recommended Practices for Operation of Aircraft, implemented in July 2016 in the tenth edition of ICAO Annex 6.
\end{abstract}

\section{Keywords:}

aviation safety, flight data recorders, ICAO

\section{Introduction}

Flight safety is influenced not only by the quality of aircraft manufacturing and the quality of on-board systems, but also by the quality of ground support, pilot skills and an air traffic control organization. Other items positively influencing flight safety are also on-board recorders of all types, out of which the most common are flight recorders. They are used mainly for reconstruction of the key flight situations and a flight record when searching for the aircraft incident causes. This type of recorders has also several other names, such as flight or data recorder, black box and in articles written in

\footnotetext{
* Corresponding author: Department of Aircraft Electrical Systems, Faculty of Military Technology, University of Defence in Brno, Kounicova 65, 66210 Brno, Czech Republic. Tel.: +420 9734450 61, Fax: +420 9734452 35, E-mail: michal.dub@unob.cz
} 
English, the most commonly used names are FDR - Flight Data Recorder, or ADR Accident Data Recorder.

The newest edition of ICAO Annex 6 divides flight recorders into two groups crash protected flight recorders and lightweight flight recorders. However, lightweight flight recorders are also crash protected, only then protection requirements do not meet the requirements for crash protected flight recorders. According to Annex 6, crash protected flight recorders comprise one or more of the following systems - a flight data recorder (FDR), a cockpit voice recorder (CVR), an airborne image recorder (AIR), a data link recorder (DLR). Lightweight flight recorders comprise one or more of the following systems - an aircraft data recording system (ADRS), a cockpit audio recording system (CARS), an airborne image recording system (AIRS), a data link recording system (DLRS) [1].

Fitting Flight Data Recorders into large commercial aircraft became mandatory after several serious crashes with neither survivors nor witnesses in mid 1950s. At that time two models of flight recorders were constructed - the General Mills (GM) Ryan Flight Recorder and the Australian Research Laboratories (ARL) Flight Memory Unit. GM Flight Recorder was based on patent of Minnesota university professor James J. Ryan and it was capable of storing four data parameters (velocity, g-force, altitude, and time) for up to 300 hours using a needle engraving into metal foil. The prototype of ARL combined a cockpit voice and data recorder and it was based on an idea of David Warren to use the voice wire recorder onboard. ARL Flight Memory Recorder was capable of storing the cockpit speech and eight instrument readings per second for the four hours [2-4].

While not the first wire recorder to be used by a flight crew, ARL device was the first to be intended and constructed as a permanent part of aircraft to help accident investigating boards. Similarly, while not the first flight-data recorder, GM device was the first to really emphasize the concept of crash protection, as well as the first to be put through a rigorous program of scientifically controlled destructive testing. Warren's and Ryan's devices were not just flight recorders, but flight recorders designed and deployed above all as accident technologies [5].

The first FDRs could only engrave 5 parameters onto a non-reusable metal foil. Czechoslovak Air Force had several Soviet manufactured aircraft with the first known recorder of type K2-717 (in Russian called barospeedograph), used for recording barometric altitude, speed and time using needle engraving into a floated whiting layer on a paper strip. This recorder was then (in the 1970s) slowly replaced by SARPP-12 recorder, using photographic recording of up to six analogue parameters and ten discrete parameters onto photographic film. The construction of flight recorders went always hand in hand with the technological abilities of the era, however, the general structure could be described as sensor - signal processing - recording.

Recorders technology has improved significantly from analogue to digital on tape, then to solid state able to record over 3000 parameters. To fulfil the expected task of revealing the causes of flight accidents, the flight recorders must fulfil the several following important requirements:

- Relevant set of recorded parameters and relevant recording length.

- Survival (no damage) of the recorded data in the case of accident.

- Speedy recovery of the crashed aircraft record.

The relevant set of flight and aircraft parameters is undoubtedly an important requirement for objective assessment of the flight incident. Selection of the parameters is entirely dependent on the size and equipment of the aircraft. Different flight record- 
er manufacturers use different approaches to the available technologies, however, at the beginning of 1980s, ICAO started to recommend recording of 32 flight and aircraft parameters in the flight recorders of airline aircrafts.

Amongst the most important flight parameters were barometric altitude, real air speed, indicated flight speed, vertical flight speed, flight course, pitch angle, roll angle, and a multiple of overload in longitudinal and perpendicular axis. Amongst recorded parameters of on-board systems were also engine revolutions, aileron and elevator positions, fuel pressure, oil pressure, hydraulic system pressure, discrete signals of aircraft configuration about aircraft landing gear status, landing flaps status, then electric generators cut off status, engine fire signals, etc.

Recording length depends on the length of the recording tape, memory size or customer request. However, to evaluate an air incident, the last 30 minutes of the recording is usually sufficient.

Survival and speedy recovery of the recording is a must for flight recorders to fulfil their purpose. The recording must be useable to evaluate the situation. Therefore, it is necessary to consider all the negative factors that can affect the recording during the aircraft accident. They are mainly mechanical forces due to an overload, impact force during an impact into the terrain, action of heat during fire, salt water attack if landed in sea, and attack of aircraft fluids including extinguishing agents.

\section{Flight Data Recorders}

Historical development of the flight recorders is best described according to the technologically available principles and recording protection. First generation of flight recorders were analogue, based on the above mentioned mechanical or photographic principles and only a small amount (in the order of units) of continuous parameters were recorded. For example, in the former Czechoslovak Air Force, Su-7 aircraft had K2-717 recorder, called Barospeedograph, recording barometric altitude, speed and time and the recording was engraved by needles into a coloured paper with a layer of floated whiting (Fig. 1).

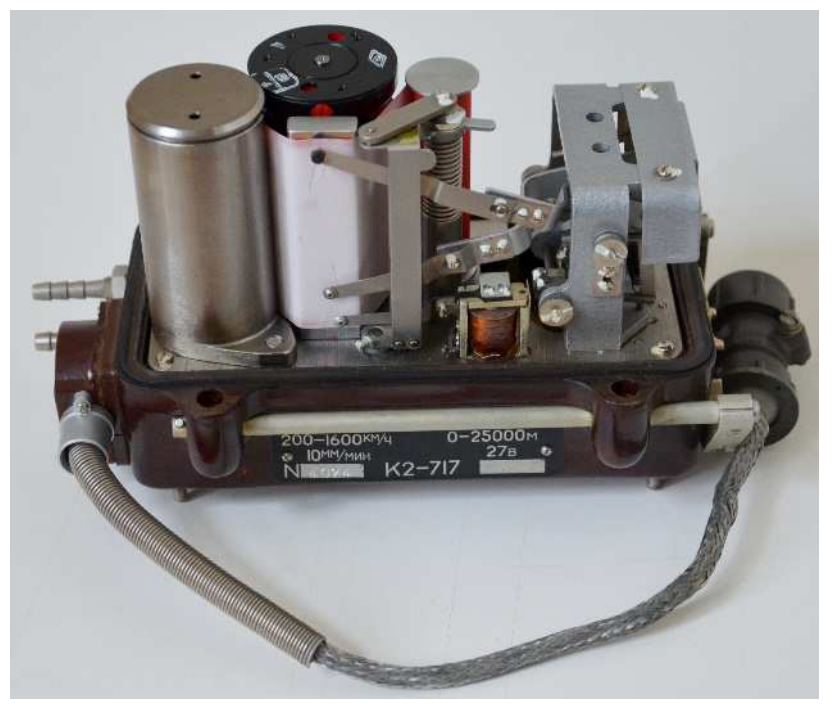

Fig. 1 K2-717 Barospeedograph 
The second generation of flight recorders (1970s and 1980s) was based on the principle of digital-magnetic recording onto a plastic or metallic magnetic strip or a wire. Apart from data recorders, also audio recorders started to appear. The Czechoslovak Air Force aircraft had PARES flight recorders (of Czechoslovak production) and TESTER, BUR and MSRP recorders (of Soviet production). The third generation of recorders (from 1990s until present) use (theoretically, for unlimited number of parameters) non-volatile FLASH or EEPROM memories and are so called recorders with solid state memory (SSFDR - Solid State Flight Data Recorder - see Fig. 2).

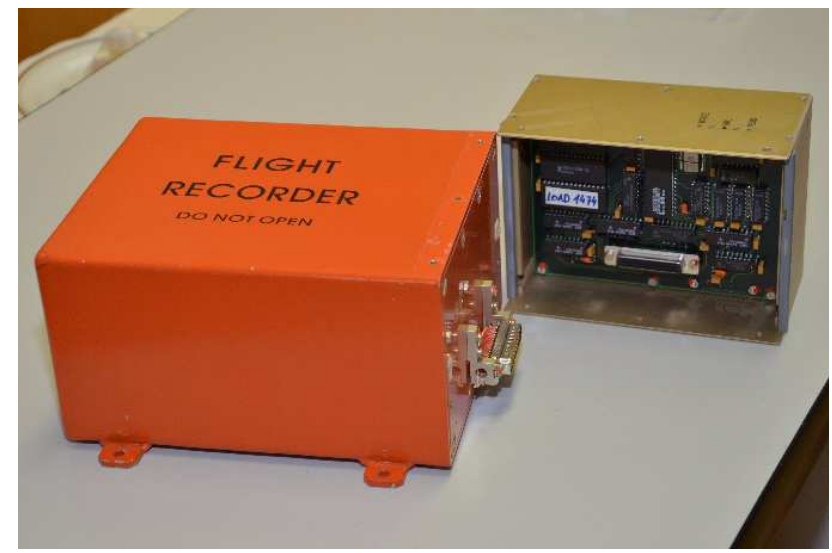

Fig. 2 Aero L-159 SSFDR by SPEEL Prague

Another classification of recorders can be sorted according to the methods for limiting the negative impact on survival and record recovery. According to this principle, two basic concepts were created already at the beginnings of the flight recorders development - crash-protected recorders (fixed, crash-protected FDRs) and deployable recorders (deployable FDRs).

Both concepts are based on the same data collection method (flight history log and aircraft systems $\log$ ) and the same data recording method or storage method in the memory unit. However, these two concepts have different methods of survival and record recovery. It is interesting to note that the two patents for these two recorder concepts, submitted to USA patent office, were only 4 years apart.

Crash-protected recorders (US patent No. 2959459) are supposed to have a permanent location in a suitable place under the aircraft body cover and should also have protection against the influence of negative factors. A suitable place for fixing the recorder is the aircraft tail part as this part is relatively undamaged during aircraft accidents and also often out of centre of fire. Currently, the majority of military and civilian aircraft are equipped with these types of recorders all over the world.

A disadvantage of the crash-protected recorders is a quite complex system of the data protection in order to match the regulations for endurance or, in other words, to be useable after the crash. In 1958, CAB (Civil Aviation Board, US agency in 19401985) created technical standard (TSO C-51) for the first generation of recorders, defining the record crash resistance as withstanding an impact with overload of $100 \mathrm{~g}$ and resisting a heat of $1100{ }^{\circ} \mathrm{C}$, over $50 \%$ of the recorder's surface during a period of 30 minutes [6].

For the generation of the digital magnetic-stripe recorders, this standard was amended in December 1965 by FAA (Federal Aviation Administration, US civil avia- 
tion authority formed in 1958) to TSO C-51a, increasing e.g. the impact resistance to $1000 \mathrm{~g}$. These two standards also define, apart from mechanical and heat resistance, the resistance to salt water attack and the resistance to operational aircraft liquids attack including extinguishing agents, as well as they also describe test methods for the flight recorders testing.

For the generation of the solid state recorders, standard TSO C-124 has been applied since 1992. This standard defines that the recording should withstand:

- Mechanical impact: $3400 \mathrm{~g}$ for 6.5 milliseconds.

- Penetration: $227 \mathrm{~kg}$ pin dropped $3 \mathrm{~m}$, each face.

- Crushing force: $22250 \mathrm{~N}$ for 5 minutes each axis.

- Fire: $1100{ }^{\circ} \mathrm{C}$ for 30 minutes.

- Seawater pressure: of $60 \mathrm{MPa}$ (depth of $6000 \mathrm{~m}$ ) for 24 hours.

- Seawater immersion: up to the depth of 3 meters for 30 days.

- Aircraft fluids (jet fuel, oil, hydraulics etc.) contact: for 48 hours.

- Extinguishing fluids contact: for 8 hours.

The fulfilment of the above mentioned requirements is technically feasible only thanks to the small dimensions of the solid state memories (board with memories covers only about $5 \%$ of the whole volume of the protected memory unit), and for example, the recording protection technology against flame is usually the know-how of the FDR manufacturer.

European organisation dealing with standards for flight recorders endurance is EUROCAE (European Organization for Civil Aviation Equipment). European standards concerning endurance have preceded the American standards that are based on the European once. For example, European standard ED 55 was accepted in May 1990 whereas TSO-C124a was accepted in January 1996. The newest standard ED 112 (merging standards for FDR and CVR, thus ED 55 and ED 56) from 2003 (ED-112A from 2013) was a baseline for TSO-C124b from 2007 (TSOC-124c from 2013) [7-8].

In order to locate the protected memory unit, the flight recorders used in flights over vast water areas, are equipped with ULB (Underwater Locator Beacon). If the aircraft crashes into the sea or the ocean, the water activates this beacon that starts transmitting 10 millisecond pulse signal every second with a frequency of $37.5 \mathrm{kHz}$. According to the actual charge of the battery, it can transmit over a period of 30-90 days. Acoustic signals of these beacons should be well audible in good conditions within the quite small range of $5 \mathrm{~km}$ if considering the size and depth of the sea and the ocean. Additional locator called ULD (Underwater Locator Device) operating at a frequency of $8.8 \mathrm{kHz}$ is attached to the airframe of airplanes performing public transport flights over maritime areas to locate aeroplane wreckage below the surface of water (i.e. increasing range) $[1,9]$.

\section{Automatic Deployable Flight Recorders}

The second concept of recorders, firstly called ejectable flight recorders and published in 1964 (US patent No. 3140847A), states that the most effective factor for survival of the recording is if the flight recorder is detached from the aircraft in an appropriate time and lands separately, away from the rest of the aircraft. However, this very idea of separating a device during crash from the aircraft to overcome its damage has already been published in 1960 (US patent No. 2959671) [10, 11].

This patent describes a deployable position indicator (current ELT - Emergency Locator Transmitter), enabling fast recovery of the crashed aircraft in unpopulated and 
inaccessible areas. Emergency Locator Transmitters ELT (also called EPIRB - Emergency Position Indicating Radio Beacon; or ELB - Emergency Locator Beacon; or PLB - Personal Locator Beacon) can be activated manually or automatically. They transmit emergency signal on the frequency of $406 \mathrm{MHZ}$ and more modern transmitters use also GPS receivers and thus it is possible to recover them fast and accurately using satellites.

Both above mentioned patents are based on the same principle - a device which needs protection from the destructive action of the crash is inserted into a housing and then attached to the aircraft so that as soon as a crash is identified, the device can be relatively easily detached from the aircraft. Thus, this device lands onto a terrain or water area separately, away from the crash epicentre and away from the destructive conditions. It is clear that impact and crash forces will be in this case much lower than on the aircraft, the device will not be exposed to high temperatures and thus less attention and money can be paid to the device protection against damage. However, for the case of landing on water, the device has to be afloat, ensuring unlimited floatability and has to have emergency signal transmitter, enabling the device's localisation.

Deployable recorders were not, according to the accessible resources, used during the development of the first and second generation flight recorders. Perhaps, it was due to the fact that the then used constructions were quite heavy and large and also that there was no option for locating the recorders using satellites. The first search and rescue satellite system Cospas-Sarsat was established already in 1979, and in 1982 was used to rescue 3 people from a small crashed aeroplane. However, only in 1988 a contract about final rescue organisation structure was signed, allowing the rescue of human lives all over the world [12].

Robert Austin, a system engineer of DRS Flight Safety and Communications Company, mentioned in his publications that deployable beacons and recorders of DRS Company have been flying in military jet planes, turbo-propeller planes and helicopters for more than 30 years. That would mean that they were used at least from 1970. However, from the above mentioned reasons, they were most likely used only regionally. In the late 1990s, DRS Company gained contracts for the modernisation of Canadian Marines patrol aircraft CP-140, F/A-18 Hornet aircraft of American Marines and Tornado aircraft of German Air Force [13-14].

The modernization consisted of replacement of existing recording systems by deployable system EAS-3000F that integrated voice and data recorder and emergency locator transmitter (CVR + FDR + ELT) into one unit. This article also stated that DRS Company had gained contracts for EAS-3000 (helicopter version of this system) for the modernisation of Canadian Cormorant Search and Rescue helicopters, United Kingdom Marines, Italian Marines and Tokio Metropolitan Police helicopters. The same article also cited that currently used deployable systems were mainly used in aircraft and helicopters of Marines, rescue systems or police and also in Norwegian helicopters of Norsk Helikopter Company, transferring workers to oil rigs in the North Sea [15].

\subsection{Location, Activation and Deploying Methods}

Constructions of the system, locations in the aircraft and deployment methods from the aircraft have been changing in line with the technological abilities of the eras. Original patent stated that the tape recorder and radio transmitter should be placed in one unit near the aircraft tail. Figure 3 shows a device with the recorder itself (26), radio trans- 
mitter (28), rocket engine (20), inertia switches kit (36-40), battery (66), thermal switch (142) and parachute (31).

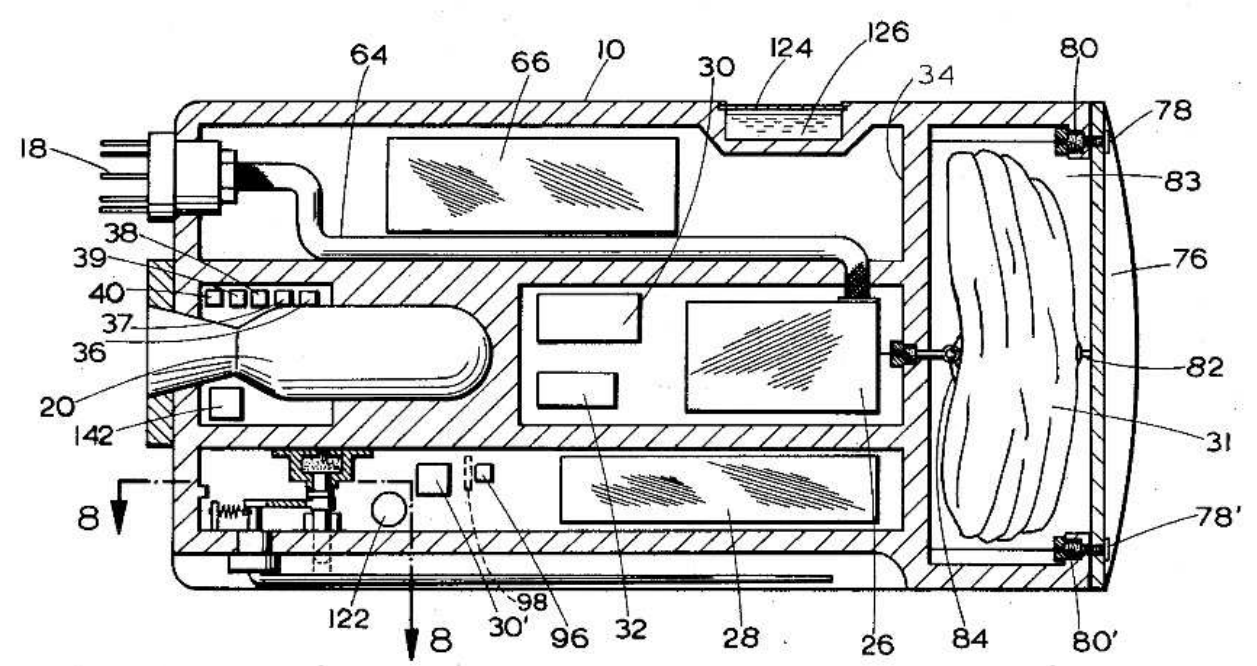

Fig. 3 Principle of ejectable recorder patented by US patent 3140847 [10]

Activation of the deployment was assured by a system of inertia switches, having their sensitive axis positioned in all possible directions of the impact or by the thermal switch in case of explosion or on-board fire. Electrical contact in any of the switches opened the door, ignited the rocket engine and then, with a certain delay, deployed the drag parachute. At the same time, the radio transmitter started transmitting a signal to locate the geographical position of the recorder. From the patent description, it is clear that the author of the patent didn't consider the aircraft crashing in a large water area the device has no means of keeping afloat and it is very likely that after submersing into the water, the radio beacon would stop working [10].

The most recent patents from 2014 state the unit should be placed near the aircraft tail in order to use aerodynamic forces when the unit is deployed. As helicopters do not reach high speeds, the aerodynamics cannot be considered when placing the recorder near the tail part of helicopters [16-17].
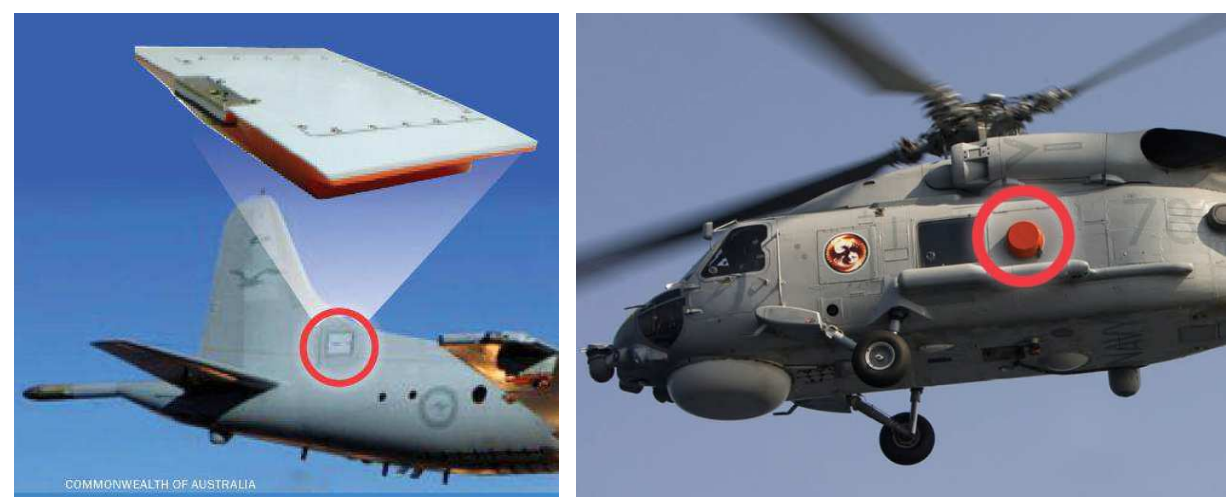

Fig. 4 ADFR installed on AP-3C Orion and S-70 Seahawk [DRS technologies] 
Depending on the used model, the deployment system consists of a set of sensors placed in various parts of the aircraft - impact sensors, airframe integrity sensors and immersion sensors $(0.9 \mathrm{~m}$ depth). The control unit is configured to activate the deployment when the deployment criteria are fulfilled. The deployment criteria are gradually evaluated and four accident risk levels are set depending on the flight mode and parameters. The system differentiates between a ground activity phase, a take-off phase, a flight phase and a landing phase. The system sensitivity to the signals coming from the sensors and deciding the recorder deployment is then increasing with the increased risk of an accident. The control unit also evaluates signals from the aircraft warning systems and warns the pilot about the failure of important aircraft systems, about the loss of altitude, oncoming collision, etc.

It is clear that, unlike the patented system in 1960s, the current systems are more sophisticated and advanced due to the availability of microprocessors and MEMS technologies. Therefore, it is a paradox that the unlimited floatability of these modern systems and at the same time the impact protection are assured by an 'ordinary' waterproof foam that fills the whole free space of the system housing. Principles of the system release and deployment can vary.

The system on F-18 aircraft uses, for a reliable deployment during an accident in high speed, a small pyrotechnical cartridge, while system DFIR 2100 for Boeings RC-135 and other subsonic aircraft uses electromagnetic principle during deployment, i.e. an electromagnet and a spring. The deployment time is in this case less than 50 milliseconds, regardless the speed and the aircraft position [13].

Many companies from all over the world are manufacturing flight recorders with protected memory, including the one from made in the Czech Republic (SPEEL Prague). However, deployable recorders are, according to the newest information, manufactured only by DRS Technologies Inc., based in Arlington, Virginia, USA [18].

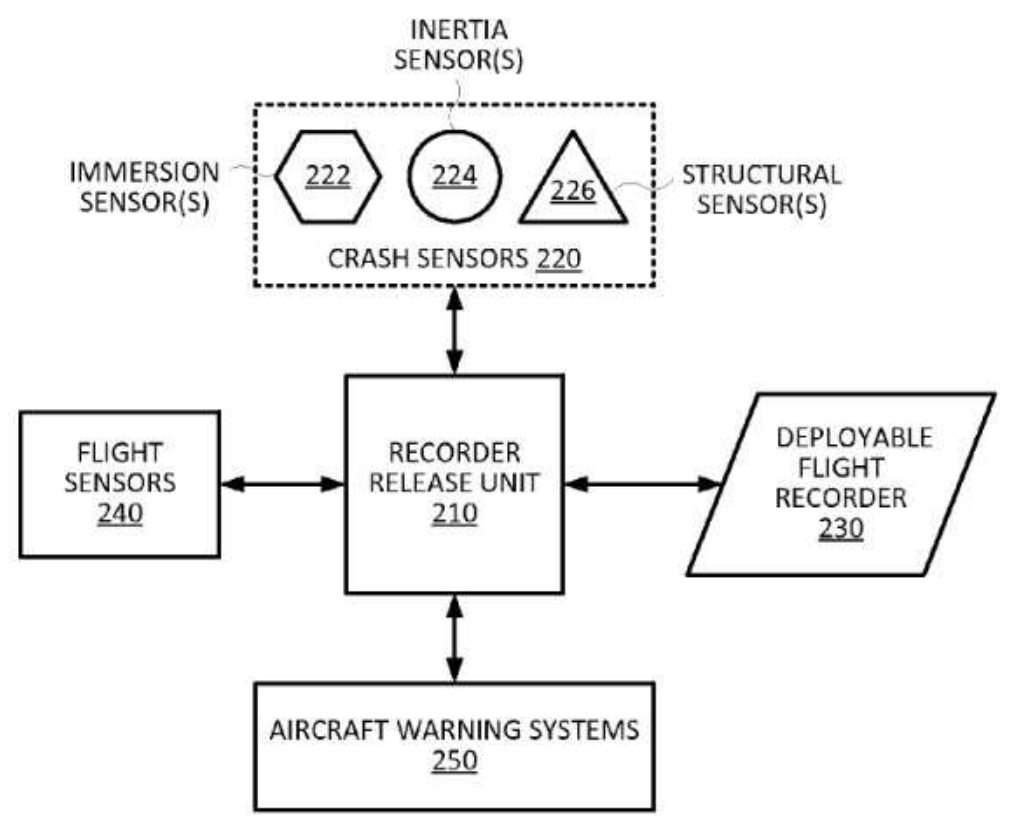

Fig. 5 ADFR deployment system structure [16] 


\subsection{Experience with Deployable Recorders in Air Traffic}

According to the manufacturer of the modern deployable recorders of EAS-3000F type, the recovery percentage is very high (more than $95 \%$ ) and the usability of the recording is $100 \%$. It means no recording has been damaged so far. The same information was confirmed by R. Austin, stating that the recovered recorders were always in a good state and only slightly damaged. In one reported case the data from the recorder on F-18 were successfully downloaded despite the fact that the aircraft landed on its tail and the system did not have a chance to deploy the recorder. A question remains, in how many cases the download was not successful [13-14].

The recovery percentage of the deployable recorders is very high. Another case is worth mentioning which happened on 29th January 2005 when the F/A-18F Super Hornet aircraft fell in the sea near Japan after an unsuccessful landing on the USS Kitty Hawk aircraft carrier and its recorder (DFIRS) was deployed successfully. However, the recorder was not recovered without any particular reason. Nearly 6 years later, the recorder was found on a sandy beach on Hawaii Island Oahu by a local surfer.

This fact and Fig. 6 show that DFIRS recorder was not mechanically damaged, corrosion caused by sea water was insignificant as the data in memory module was not damaged and was successfully downloaded. The important fact is that the recorder floated nearly 6 years and was practically unsinkable [19].
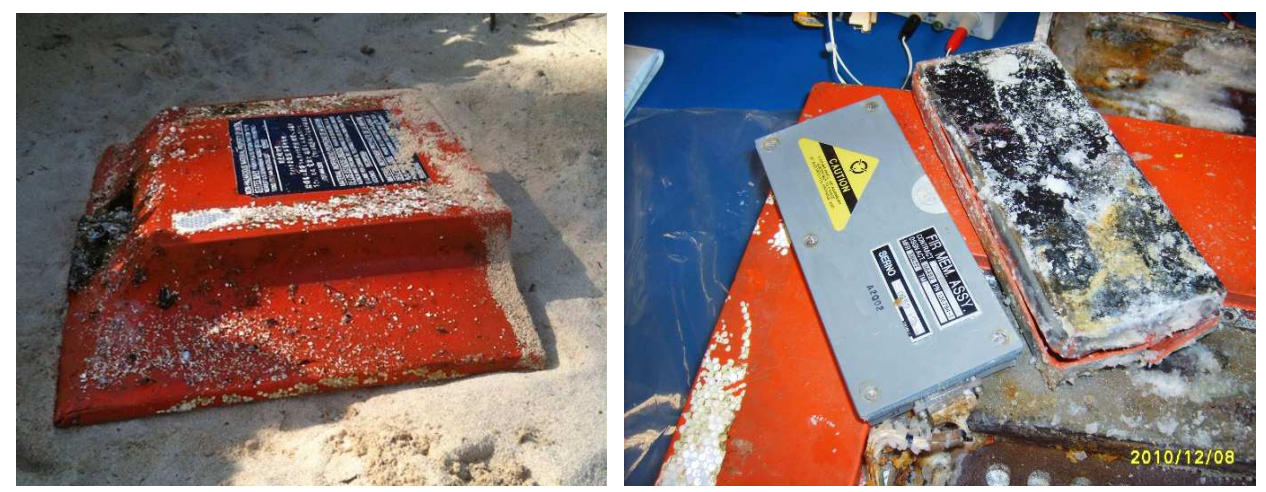

Fig. 6 DFIR found on the beach of Oahu, Hawaii [20]

\subsection{ICAO Standards and Recommended Practices}

According to the new edition of ICAO Annex 6, automatic deployable flight recorder containers shall be painted a distinctive orange colour (surface visible from outside the aircraft may be of another colour), they shall carry reflective material to facilitate their location and they shall have an integrated automatically activated ELT [1].

The following requirements shall apply to an ADFR:

- deployment shall take place when the aircraft structure has been significantly deformed;

- deployment shall take place when an aircraft sinks in water;

- ADFR shall not be capable of manual deployment;

- the ADFR shall be able to float on water;

- the ADFR deployment shall not compromise the safe continuation of the flight; 
- the ADFR deployment shall not significantly reduce the chance of survival of the recorder and of successful transmission by its ELT;

- the ADFR deployment shall not release more than one piece;

- an alert shall be made to the flight crew when the ADFR is no longer captive to the aircraft;

- the flight crew shall have no means to disable ADFR deployment when the aircraft is airborne;

- the ADFR shall contain an integrated ELT, which shall activate automatically during the deployment sequence. Such ELT may be of a type that is activated in flight, providing information from which a position can be determined;

- and the integrated ELT of an ADFR shall satisfy the same requirements as an ELT required to be installed on an aircraft. The integrated ELT shall at least have the same performance as the fixed ELT to maximize detection of the transmitted signal.

\section{Conclusions}

Each concept of the flight recorder brings certain advantages and disadvantages. The disadvantages are going to show only in particular unsuitable conditions for the particular recorder type. There are many other recent cases, for example MH370 aircraft of Malaysia Airlines, on 7th March 2014, when after 41 minutes of flight, the aircraft lost contact with the control centre and stopped replying to the radar responder. The aircraft (and the onboard recorder with protected memory) have not been so far recovered. As for the deployable recorder, it is technically possible that the system would wrongly evaluate the situation as an emergency, deploy the recorder and the plane would continue being airborne. Then, the recording would be lost for the rest of the flight. Current trend of the onboard recorders includes integration of the individual recorder types into one unit, making their size smaller and improving the data protection against harsh environments.

Also, current aircraft accidents and disasters drive the improvement for protection of the aircraft data log and the flight data log. One of the first improvement ideas was to increase the battery capacity for acoustic beacon to extend the working time of the beacon from 30 to 90 days and thus increase the chances of recovering the recorders (mandatory from 1 January 2018). Two advanced options of flight recorders installation were also suggested. The first option required installing two combined CVR/FDR recorders with protected memory. One would be installed near the aircraft nose, the second near the aircraft tail and both would record the same voice and data information. The second option would require installation of two different recorders one recorder with protected memory and the second recorder would be a deployable recorder. Then, the aircraft would have both types of recorders. Airbus SE Company now considers utilising both options and the company will be certified for installations of DFIRS for aircraft A350 in 2019 [1,21].

The last known idea introduced a concept for ground collecting and analysing flight data. The main idea of this system is that all information about the aircraft and flight would be transferred online using ground communication stations or satellite networks and then stored at the ground monitoring station for later analysis. Special software would identify a non-standard behaviour of the aircraft in real time (for example a flight diversion from the usual route, unusual position or vertical speed of the aircraft, etc.) and apply a relevant corrective action if needed. This idea was most 
likely planned mainly for civilian airline aircraft as it may attract a few concerns about the complexity and financing of the implementation, international relations, operation system responsibilities and securing the system against political changes or similar events [22].

Based on the air transport development, covering mainly an increase of power and flight density, it is clear that the need for flight recorders or any other device for analysing emergency situations is and always will be always increasing. Current modern technologies are enabling miniaturisation, back-ups, unsuitable conditions protection, large data transfers, implementation of the earlier-proposed but not-yet-implemented principles, but cost will always be considered when implementing technologies for increasing flight reliability and safety. On the one hand, manufacturers can provide the best equipped and the most reliable aircraft, but on the other hand, there are many cases where financial gain or political issues were of more interest than flight safety.

\section{Acknowledgement}

The work presented in this article has been supported by the Ministry of Defence of the Czech Republic (UoD development program "Research of sensor and control systems to achieve battlefield information superiority").

\section{References}

[1] Annex 6 to the Convention on International Civil Aviation. Part I - International Commercial Air Transport - Airplanes. Tenth edition. Montreal: ICAO, 2016.

[2] US Patent 2959459 Flight Recorder [on-line]. Patented November 8, 1960. [cit. 2017-09-25]. Available from <http://pdfpiw.uspto.gov/.piw?PageNum=0\&docid $=02959459>$.

[3] WARREN, D. A Device for Assisting Investigation into Aircraft Accidents. Melbourne: Aeronautical Research Laboratories, 1954. Mechanical Engineering Technical Memorandum 142.

[4] SEAR, J. The ARL 'Black Box' Flight Recorder - Invention and Memory. Melbourne: University of Melbourne, 2001, 37 p. Thesis Ref. 14567 for Bachelor of Arts (Honours), Department of History, Faculty of Arts.

[5] SIEGEL, G. Technologies of Accident: Forensic Media, Crash Analysis, and the Redefinition of Progress. Chapel Hill: University of North Carolina, 2005. 245 p.

[6] ROSENBAUER, J.E. Modern Aircraft Accident Investigation Equipment and Techniques [on-line]. Lockheed Horizons. Winter 1981-1982, p. $20-27$ [cit. $2017-$ 09-24]. Available from <https://macmanx.com/modern-aircraft-accidentinvestigation-equipment-and-techniques $/>$.

[7] TSO: Technical Standard Orders ${ }^{\odot}$ [on-line]. 2017 [cit. 2017-10-15]. FAA. Available from $<$ http://rgl.faa.gov/>.

[8] Eurocae ${ }^{\odot}$ [on-line]. 2017 [cit. 2017-09-25]. Available from <https://www. eurocae.net>.

[9] US Patent 4951263 Spread Spectrum Underwater Location Beacon System [on-line]. Patented August 21, 1990. [cit. 2017-08-29]. Available from $<$ http://pdfpiw.uspto.gov/.piw?PageNum=0\&docid=04951263>. 
[10] US Patent 3140847 Ejectable Flight Recorder [on-line]. Patented July 14, 1964. [cit. 2017-08-29]. Available from <http://pdfpiw.uspto.gov/.piw?PageNum=0\& docid $=03140847>$.

[11] US Patent 2959671 Crash Position Indicator For Aircraft [on-line]. [cit. 201708-29]. Available from <http://pdfpiw.uspto.gov/.piw?PageNum=0\&docid $=0295$ 9671>. Patented November 8, 1960.

[12] LEVESQUE, D. (Ed.) The History and Experience of the International CospasSarsat Programme for Search and Rescue. Paris: International Astronautical Federation, 2016 [cit. 2017-09-20]. Available from <http://www.iafastro.org/wpcontent/uploads/2017/01/Cospas-Sarsat-Report-1.pdf $>$.

[13] AUSTIN, R.P. The Use Of Deployable Flight Recorders in Dual Combi Recorder Installations [on-line]. 1999 [cit. 2017-09-25]. Available from $<$ http://www.iasa.com.au/folders/Publications/pdf_library/austin.pdf $>$.

[14] DRS Technologies Awarded \$2 Million Contract to Provide Emergency Avionics Systems for Canadian CP-140 Aircraft. Business Wire. 1998, December 3 [cit. 2017-08-25]. Available from <https://www.thefreelibrary.com/DRS+Technolo gies+Awarded+\%242+Million+Contract+to+Provide+Emergency ...a053344501>.

[15] DRS Technologies Awarded Contract to Produce Deployable Flight Recorders for U.S. Navy Super Hornets. Business Wire. 2004, August 24 [cit. 2017-07-02]. Available from <https://www.thefreelibrary.com/DRS+Technologies+Awarded+ Contract+to+Produce+Deployable+Flight...-a064817942>.

[16] US Patent 8706357 Flight Recorder Deployment System and Method [on-line]. Patented April 22, 2014. [cit. 2017-08-29]. Available from <http://pdfpiw. uspto.gov/.piw?PageNum=0\&docid=08706357>.

[17] US Patent 9296489 Flight Recorder Deployment Mechanism [on-line]. Patented March 29, 2016. [cit. 2017-08-29]. Available from <http://pdfpiw.uspto.gov/.piw ?PageNum $=0 \&$ docid $=09296489>$.

[18] ROSENBACH, von A. and SASIDHARAN, A. Jane's Flight Avionics 20162017. HIS Jane's, 2015. ISBN 978-0-7106-3210-4.

[19] TEGLER. J. DFIRS Makes a 4,000 Mile Journey to Recovery [on-line]. 14 June 2011 [cit. 2017-08-29]. Defense Media Network. Available from $<$ http://www.defensemedianetwork.com/stories/dfirs-makes-4000-mile-journeyrecovery/>.

[20] Surfer Finds $21^{\text {st }}$ Century 'Message in a Bottle' on Hawaii Beach [on-line]. 18 March 2011 [cit. 2017-08-29]. Navair News. Available from <http://www. navair.navy.mil/index.cfm?fuseaction=home.NAVAIRNewsStory\&id=4530>.

[21] WALtON, J. Airbus To Introduce Deployable Black Boxes [on-line]. 27 June 2017 [cit. 2017-09-25]. Available from <http://rotate.aero/blog/entry/airbus-tointroduce-deployable-black-boxes $>$.

[22] KAVI, K.M. Beyond the Black Box. IEEE Spectrum, 2010, vol. 47, no. 8, p. 4651. DOI 10.1109/MSPEC.2010.5520630. 